\title{
Composição florística e estrutura da comunidade de epífitas vasculares em uma área de ecótono em Campo Mourão, PR, Brasil
}

\author{
Henrique Cesar Lopes Geraldino ${ }^{1,2}$, Marcelo Galeazzi Caxambú ${ }^{1}$ e Débora Cristina de Souza ${ }^{1}$
}

Recebido em 2/04/2009. Aceito em 22/03/2010

RESUMO - (Composição florística e estrutura da comunidade de epífitas vasculares em uma área de ecótono em Campo Mourão, PR, Brasil). O presente estudo foi realizado em uma área de ecótono de aproximadamente 30 hectares entre Floresta Estacional Semidecidual e Floresta Ombrófila Mista, localizada na Capela do Calvário, município de Campo Mourão, PR. Para a análise fitossociológica foram selecionados 80 forófitos. No levantamento total foram encontradas 61 espécies, 39 gêneros e 13 famílias de epífitas (10 de Pteridófitas e 51 de Magnoliófitas). As famílias mais ricas foram: Orchidaceae (38\%), Bromeliaceae e Polypodiaceae (13\%), Cactaceae (11\%) e Piperaceae (8\%), que juntas compõem 83\% das espécies amostradas. Os gêneros Tillandsia (Bromeliaceae) e Peperomia (Piperaceae) foram os mais ricos, com cinco espécies. A anemocoria foi constatada em $67 \%$ das espécies e $86 \%$ foram classificadas como holoepífitas verdadeiras. Das 61 espécies inventariadas, 43 ocorreram nas áreas de amostragem, sendo cinco em maior freqüência: Microgramma squamulosa, Pleopeltis angusta, Tillandsia loliacea, Tillandsia recurvata e Pecluma sicca. O índice de Shannon (H') registrado para a área foi de 3,175 e a equabilidade (J) 0,863. Foram encontradas nove espécies epifíticas restritas a apenas um forófito. Microgramma squamulosa foi a espécie mais importante em toda área amostral. $\mathrm{O}$ trecho de vegetação em área de interflúvio, por apresentar estágio avançado de desenvolvimento, teve riqueza superior à área de vegetação ribeirinha.

Palavras-chave: Diversidade, Floresta Estacional Semidecidual, Floresta Ombrófila Mista, epifitismo, fitossociologia

\begin{abstract}
Floristic composition and structure of the vascular epiphyte community in a transition area at Campo Mourão, Paraná, Brazil). This study was conducted in a transition area of approximately 30 hectares between Semideciduous Forest and Araucaria Forest located in the Capela do Calvário, at Campo Mourão, Paraná. For the phytosociological analysis 80 phorophytes were selected. The survey found 61 species, 39 genera and 13 families of epiphytes (10 pteridophytes and 51 magnoliophytes). The richest families were: Orchidaceae (38\%), Bromeliaceae and Polypodiaceae (13\%), Cactaceae $(11 \%)$ and Piperaceae (8\%), which together make up $83 \%$ of the sampled species. Tillandsia (Bromeliaceae) and Peperomia (Piperaceae) were the richest genera, each with five species. Anemochory was found in $67 \%$ of the species and $86 \%$ were classified as true holoepiphytes. Of the 61 species listed, 43 occurred in the sample area; the following five had the highest frequency: Microgramma squamulosa, Pleopeltis angusta, Tillandsia loliacea, Tillandsia recurvata and Pecluma sicca. The Shannon Index ( $\left.\mathrm{H}^{\prime}\right)$ recorded for the area was 3.175 and evenness $(\mathrm{J}) 0.863$. Nine epiphytic species were restricted to just one phorophyte. Microgramma squamulosa was the most important species over the entire sample area. The vegetation of the interfluvial area, in an advanced stage of development, was richer than the riverside vegetation.
\end{abstract}

Key words: Diversity, Seasonal Semideciduous Forest, Mixed Ombrophilous Forest, epiphytism, phytosociology

\section{Introdução}

A importância ecológica do epifitismo nas comunidades florestais consiste na manutenção da diversidade biológica e no equilíbrio interativo: as espécies epifíticas proporcionam recursos alimentares (frutos, néctar, pólen, água) e microambientes especializados para a fauna do dossel, constituída por uma infinidade de organismos voadores, arborícolas e escansoriais (Waechter 1992). As aves também podem utilizar vários recursos de epífitas, tais como frutos, flores, sementes, água, invertebrados, material e local para nidificação (Coelho et al. 2003). As epífitas podem servir como indicadores de estágio sucessional da floresta, uma vez que comunidades secundárias apresentam diversidade epifítica menor do que comunidades primárias (Budowski 1963; 1965 apud Dislich 1996).

Os epífitos se estabelecem diretamente sobre o tronco, galhos, ramos ou sobre as folhas das árvores, sendo estas plantas hospedeiras denominadas de forófitos (Dislich \& Mantovani 1998). Tem-se observado que as epífitas apresentam várias adaptações que as capacitam a ocupar o dossel da floresta. Estas adaptações consideram características como suporte, hábito de crescimento e formas de obtenção de água, luz e nutrientes (Benzing 1990).
Além destas adaptações, os epífitos desenvolvem mecanismos próprios para sobreviverem às estações mais secas, podendo captar e reter água em suas estruturas. De acordo com Benzing (1995), tais mecanismos podem ser: pseudobulbos (Orchidaceae); suculência de raízes, caules e folhas (Gesneriaceae, Piperaceae, Cactaceae, Orchidaceae); velame das raízes, que é um tecido morto que se incha para reter o excesso de água e reduzir a evaporação (Orchidaceae, Araceae); e escamas foliares e cisternas acumuladoras de água, formadas pelo imbricamento das bainhas foliares (Bromeliaceae). Já as Pteridófitas (samambaias e avencas), de acordo com Rizzini (1997), apresentam uma estratégia denominada poiquiloidria: podem dessecar a fronde e subsistir com pequena fração de água tomada da atmosfera, saturam-se prontamente quando chove e prosseguem em suas atividades vitais até novo dessecamento.

Segundo Kress (1986), as epífitas estão distribuídas em 84 famílias e representam $10 \%$ de toda flora vascular, sendo mais abundantes principalmente nos Neotrópicos.

O estado do Paraná, com apenas $2,5 \%$ da superfície brasileira, detém em seu território a grande maioria das principais unidades fitogeográficas que ocorre no país. $\mathrm{Na}$ região de Campo Mourão as principais formações florestais são a Floresta Estacional Semidecidual e Floresta Ombrófila

\footnotetext{
1 Universidade Tecnológica Federal do Paraná, Campo Mourão, PR, Brasil

2 Autor para correspondência: henriqueclg@hotmail.com
} 
Mista. Segundo Roderjan et al. (2002), nas regiões norte e oeste do estado e nos vales dos rios formadores da bacia do Rio Paraná, abaixo dos 800 metros de altitude, define-se a região com Floresta Estacional Semidecidual. Já na porção oeste da Serra do Mar, ocupando as áreas planálticas do estado, situa-se a região com Floresta Ombrófila Mista (floresta com araucária), ocorrendo entre 800 e 1200 metros de altitude, podendo eventualmente ocorrer acima desses limites. Ainda de acordo com Roderjan et al. (2002), na região oeste do Paraná a Floresta Ombrófila Mista e a Floresta Estacional Semidecidual podem ser encontradas na forma de um ecótono, caracterizado como a interpenetração de espécies características das duas grandes unidades geográficas existentes. Para Odum (1972), ecótono é a transição entre duas ou mais comunidades diferentes. É uma zona de união ou um cinturão de tensão que poderá ter extensão linear considerável, porém mais estreita que as áreas das próprias comunidades adjacentes. A comunidade do ecótono pode conter organismos de cada uma das comunidades que se entrecortam, além dos organismos característicos.

O presente estudo teve como objetivo realizar um levantamento da flora epifítica em uma área de ecótono de Floresta Estacional Semidecidual com Floresta Ombrófila Mista, buscando desenvolver e comparar seus respectivos padrões de diversidade e estabelecer parâmetros fitossociológicos, contribuindo para o conhecimento da flora local, sobretudo da comunidade de epífitas vasculares, uma vez que existem poucos trabalhos publicados para a região.

\section{Material e métodos}

O município de Campo Mourão está localizado na mesorregião Centro Ocidental do Paraná, compreendido no terceiro Planalto Paranaense entre as coordenadas $23^{\circ} / 57^{\prime} / 18,26^{\prime \prime}$ a $24^{\circ} / 17^{\prime} / 53,21^{\prime \prime}$ Sul e $52^{\circ} / 32^{\prime} / 41,16^{\prime \prime}$ a $52^{\circ} / 11$ '/10,36" Oeste, com média altitudinal de 630 metros (IBGE 1997). A topografia é plana e ligeiramente ondulada e pertence à bacia hidrográfica do Rio Ivaí, com seu afluente mais importante o Rio do Campo (IBGE 1997).

Ocorrem no município diferentes classes de solos, identificados como latossolos vermelhos, nitossolos vermelhos e neossolos litólicos, sendo estes encontrados em locais de ocorrências do basalto; já nas áreas de ocorrência do arenito ocorrem os latossolos vermelhos e argissolos (Souza 2003).

O clima, de acordo com a classificação climática de Köppen, é classificado como Cfa: clima subtropical úmido mesotérmico, com verões quentes e geadas pouco freqüentes, com tendência de concentração das chuvas nos meses de verão, sem estação seca definida, com as seguintes médias anuais: temperatura dos meses mais quentes superior a $22^{\circ} \mathrm{C}$ e dos meses mais frios inferior a $18^{\circ} \mathrm{C}$; temperatura média de aproximadamente $20^{\circ} \mathrm{C}$; chuvas variando entre 1.300 e $1.600 \mathrm{~mm}$; umidade relativa do ar $75 \%$; índice hídrico entre os níveis 20 e 60 e ausência de deficiência hídrica. Os ventos predominantes na região são os de quadrante nordeste, apresentando probabilidade de geadas nos meses de inverno, quando sopram de sul e sudoeste (Maack 1981).

A cobertura vegetal nativa de Campo Mourão é formada por Floresta Estacional Semidecidual Montana, Floresta Ombrófila Mista Montana e áreas de transição entre as mesmas (Roderjan et al. 2002). Possui também pequenos fragmentos de Cerrado (Hatschbach \& Ziller 1995).

O presente estudo foi desenvolvido em uma propriedade particular denominada "Capela do Calvário", localizada aos fundos do Jardim Tropical II no município de Campo Mourão, PR, com área florestal de aproximadamente 30 hectares (Fig. 1). Seus limites são terrenos agrícolas cultivados e uma represa no Rio do Campo, que atravessa a propriedade de sul a norte. Na área da Capela do Calvário podem ser encontradas duas tipologias vegetais, a Floresta Estacional Semidecidual e a Floresta Ombrófila Mista. Estas, porém, se apresentam interpenetradas, constituindo uma área de ecótono, caracterizada pela presença de indivíduos típicos de ambas as formações. Pode-se observar também a presença de pequenos capões remanescentes, vegetação de influência fluvial, e alguns sítios em estágio inicial de regeneração. O solo predominante é latossolo-roxo, existindo áreas de neossolo flúvico junto ao rio que corta a área de estudo, além de áreas com afloramento de rocha basáltica.

Para o inventário florístico dos epífitos vasculares foram realizadas excursões semanais durante o período de agosto de 2005 a agosto de 2006 e todos os epífitos encontrados férteis foram coletados através da escalada natural do forófito, com o auxílio de tesoura de poda alta e eventualmente com uma escada de cinco metros, conjugada a outras técnicas. A observação visual foi feita com o auxílio de binóculo e o registro do material fotográfico com câmera digital. Alguns epífitos encontrados em estado vegetativo foram cultivados até apresentarem estruturas férteis e, posteriormente, submetidos ao processo de herborização. Os forófitos também foram coletados seguindo procedimentos usuais em levantamentos florísticos (Marchiori 1995; Fidalgo \& Bononi 1989). Todo material foi incluído no acervo do Herbário (HCF) da Universidade Tecnológica Federal do Paraná, campus Campo Mourão. As identificações foram feitas por meio de bibliografia especializada, por comparação e com auxílio de especialistas do Museu Botânico Municipal de Curitiba (Herbário MBM). Os nomes dos táxons foram verificados na base nomenclatural do Missouri Botanical Garden/W3tropicos (2009). As Angiospermas foram organizadas segundo o sistema APG-“Angiosperm Phylogeny Group" (Stevens 2006), as Pteridófitas seguiram Smith et al. (2006) e especificamente para a subtribo Pleurothallidinae (Orchidaceae) foi seguida a proposta de classificação de Pridgeon \& Chase $(2001,2002)$.

Ao todo foram analisados 80 forófitos, escolhidos aleatoriamente e divididos em duas áreas amostrais, cada uma com 40 árvores. A primeira, denominada "vegetação de interflúvio" trata-se de um ambiente antropizado, margeado por duas estradas e com alguns indivíduos esparsos de espécies exóticas plantados no local (Eucalyptus sp.). De maneira geral, é formada por indivíduos arbóreos com altura superior a 15 metros, bem espaçados em meio à vegetação rasteira. A segunda área, denominada "vegetação ribeirinha" está localizada próxima à margem do rio, sendo um local úmido e sombreado, com árvores jovens e poucos indivíduos remanescentes. Possui vegetação mais densa, com algumas clareiras em fase inicial de sucessão.

Os forófitos foram tomados como unidades amostrais naturais, tendo sido incluídas apenas árvores com DAP (diâmetro à altura do peito, 1,30 m) mínimo de $10 \mathrm{~cm}$. A contagem dos epífitos presentes em cada forófito foi realizada por meio de inspeção visual, onde se considerou um indivíduo todas as plantas isoladas e as colônias ou grupos compactos de plantas, com limites bem definidos e distintamente separados de outros, da mesma espécie. No caso de plantas como Barbosella porschii, Microgramma squamulosa e Peperomia circinnata, as colônias foram separadas em intervalos de $15 \mathrm{~cm}$ e cada intervalo contabilizado como um indivíduo.

A categoria ecológica dos epífitos foi definida de acordo com os critérios adotados por Benzing (1990), em cinco grupos: holoepífitas verdadeiras (plantas que em nenhum momento de sua vida mantêm contato com o solo, maioria das Orchidaceae); holoepífitas facultativas (plantas que podem crescer normalmente sobre o solo ou em árvores, maioria das Bromeliaceae) e holoepífitas acidentais (plantas que, embora não possuam nenhuma adaptação para o hábito epifítico, podem, ocasionalmente, crescer sobre outros vegetais) e também hemiepífitas primárias (espécies que germinam sobre os forófitos e posteriormente estabelecem contato com o solo através de raízes geotrópicas pendentes ou adpressas aos ramos e fustes, como as figueiras mata-pau, Ficus spp.) e hemiepífitas secundárias (espécies que germinam no solo e, posteriormente, estabelecem contato com um forófito, perdendo a ligação com o solo por meio da degeneração basal do sistema radical, como por exemplo, Philodendron entre as Araceae).

Para cada espécie também foi registrada a sua distribuição vertical no forófito, sendo este dividido em três partes: a primeira parte o fuste inferior (do solo até sua metade); a segunda parte o fuste superior (da metade para a copa) e a terceira parte a copa propriamente dita. Esta avaliação mostra as estratégias adaptativas desenvolvidas pelas epífitas em relação à sua posição no forófito. De acordo com Benzing (1990), essa distribuição vertical de epífitos em variados intervalos de altura decorre de fatores como busca de luminosidade, umidade e condições do substrato.

A síndrome de polinização seguiu Proctor et al. (1996) e a síndrome de 


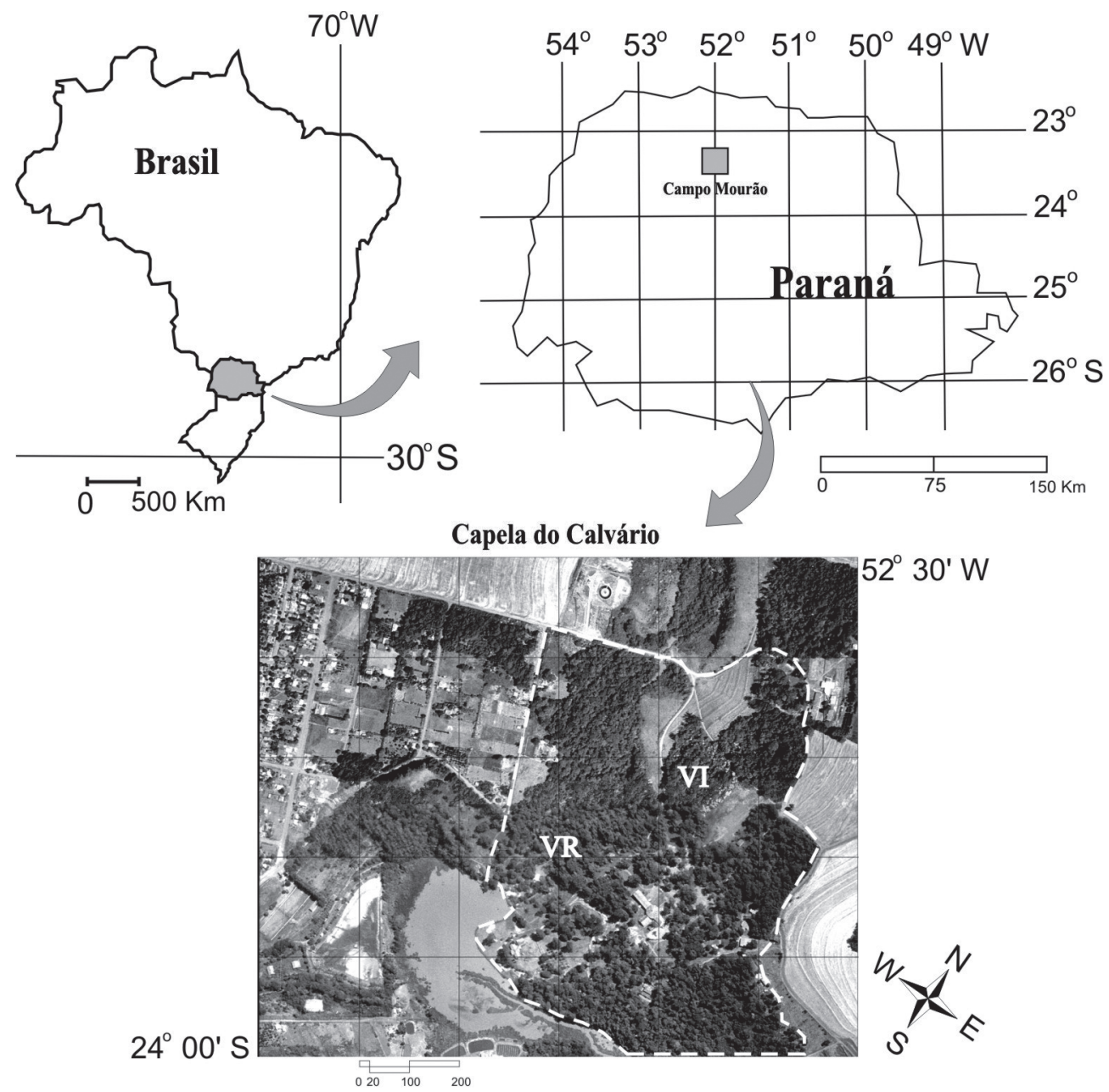

Figura 1. Localização da área de estudo na Capela do Calvário, situada em Campo Mourão, PR. Áreas de amostragem: VI - Vegetação de interflúvio e VR - Vegetação ribeirinha. Adaptado de Maack (1950).

dispersão Madison (1977), sendo relatadas apenas por meio de observação, sem estudos específicos. Ainda sobre a dispersão, também foram verificados os tipos de diásporos, sendo classificados nas seguintes categorias: diásporos diminutos (de dimensões próximas ou inferiores a $1 \mathrm{~mm}$ ) diásporos planadores (dotados de estruturas para planar) e diásporos carnosos ou viscosos (frutos indeiscentes).

Para a análise das relações de abundância entre as espécies encontradas foram utilizados os seguintes parâmetros fitossociológicos: densidade relativa (DR), freqüência absoluta e relativa sobre indivíduos forofíticos (FAI e FRI), freqüência absoluta e relativa sobre espécies forofíticas (FAS e FRS) e também o valor de importância epifítico (VIE) obtido pela média das freqüências estimadas. Estes valores foram empregados para o total de epífitas amostradas e também para o total de epífitas de cada área amostral.

A densidade relativa é a proporção do número de indivíduos de uma espécie em relação ao número total de indivíduos amostrados, em percentagem (Martins 1993). A ocorrência sobre indivíduos forofíticos é correspondente à freqüência, sendo as árvores suporte consideradas como unidades amostrais. Freqüência é definida como a probabilidade de se encontrar uma espécie numa unidade amostral (Chapman 1976). A ocorrência absoluta sobre espécies forofíticas é dada pelo quociente entre o número de espécies forofíticas que apresentam a espécie de epífita e o número total de árvores amostradas.

Também foram desenvolvidos alguns parâmetros evidenciando as ocorrências dos epífitos nos forófitos, a partir das médias de ocorrências de indivíduos epifíticos e espécies epifíticas para cada forófito, além dos desvios-padrão e coeficientes de variação.
O parâmetro de diversidade foi calculado pelo índice de Shannon, visando o estabelecimento de relações entre riqueza e abundância das epífitas com os forófitos, e também a equabilidade de Pielou, que avalia a participação proporcional das espécies presentes. As fórmulas empregadas para estas análises seguiram Waechter (1992) e Dislich (1996).

\section{Resultados e discussão}

No levantamento florístico foram encontradas 61 espécies de epífitas vasculares, distribuídas em 39 gêneros e 13 famílias, sendo 10 de Pteridophyta e 51 de Magnoliophyta (Tab. 1 e Fig. 2).

As famílias com maior riqueza específica foram: Orchidaceae (38\%), Bromeliaceae e Polypodiaceae (13\%), Cactaceae (11\%) e Piperaceae (8\%), que juntas compõem $83 \%$ das espécies amostradas. Destacaram-se pela riqueza florística os gêneros Tillandsia (Bromeliaceae) e Peperomia (Piperaceae) com cinco espécies, Acianthera (Orchidaceae) com quatro espécies e Lepismium (Cactaceae) com três espécies.

A síndrome anemocórica foi detectada em $67 \%$ das espécies, com maior freqüência em Orchidaceae, Pteridophyta e a maioria de Bromeliaceae, enquanto a zoocórica 
Tabela 1. Epífitas vasculares encontradas na Capela do Calvário em Campo Mourão, PR, com suas respectivas categorias ecológicas (CE): HLV - holoepífita verdadeira, HLF - holoepífita facultativa, HLA - holoepífita acidental, HMP - hemiepífita primária, HMS - hemiepífita secundária; síndromes de polinização (SP): ANF - anemofilia, ENT - entomofilia, ORN - ornitofilia; síndromes de dispersão (SD): ANE - anemocoria, AUT - autocoria, ZOO - zoocoria; tipo de diásporo (DP): CAR - carnoso, DIM - diminuto, PLA - planador, VIS - viscoso, IND - indeterminado; (HCF) número de registro no herbário.

\begin{tabular}{|c|c|c|c|c|c|}
\hline FAMÍLIA / ESPÉCIE & $\mathrm{CE}$ & SP & SD & DP & $\mathrm{HCF}$ \\
\hline \multicolumn{6}{|l|}{ ARACEAE (1) } \\
\hline Philodendron bipinnatifidum Schott ex Endl. & HMS & ENT & $\mathrm{ZOO}$ & CAR & 4676 \\
\hline \multicolumn{6}{|l|}{ ASPLENIACEAE (1) } \\
\hline Asplenium scandicinum Kaulf. & HLV & - & ANE & DIM & 3648 \\
\hline \multicolumn{6}{|l|}{ BROMELIACEAE (8) } \\
\hline Aechmea distichantha Lem. & HLF & ORN & ANE & CAR & 2778 \\
\hline Billbergia alfonsi-joannis Reitz & HLV & ORN & $\mathrm{ZOO}$ & CAR & 3672 \\
\hline Billbergia nutans $\mathrm{H}$. Wendl. ex Regel & HLV & ORN & ANE & CAR & 3264 \\
\hline Tillandsia loliacea Mart. ex Schult. f. & HLV & ORN & ANE & PLA & 3602 \\
\hline Tillandsia meridionalis Baker & HLV & ORN & ANE & PLA & 3608 \\
\hline Tillandsia recurvata $(\mathrm{L}.) \mathrm{L}$. & HLV & ORN & ANE & PLA & 3674 \\
\hline Tillandsia tenuifolia $\mathrm{L}$. & HLV & ORN & ANE & PLA & 3262 \\
\hline Tillandsia tricholepis Baker & HLV & ORN & ANE & PLA & 3603 \\
\hline \multicolumn{6}{|l|}{ CACTACEAE (7) } \\
\hline Cereus hildmannianus K. Schum. & HLA & ENT & $\mathrm{ZOO}$ & CAR & 6524 \\
\hline Epiphyllum phyllanthus (L.) Haw. & HLV & ENT & $\mathrm{ZOO}$ & CAR & 3652 \\
\hline Lepismium crussiforme (Vell.) Miq. & HLV & ENT & $\mathrm{ZOO}$ & CAR & 3610 \\
\hline Lepismium lumbricoides (Lem.) Barthlott & HLV & ENT & $\mathrm{ZOO}$ & CAR & 3609 \\
\hline Lepismium warmingianum (K. Schum.) Barthlott & HLV & ENT & $\mathrm{ZOO}$ & CAR & 2795 \\
\hline Rhipsalis cereuscula Haw & HLV & ENT & $\mathrm{ZOO}$ & CAR & 3607 \\
\hline Rhipsalis floccosa Salm-Dyck ex. Pfeiff. & HLV & ENT & $\mathrm{ZOO}$ & CAR & 3270 \\
\hline \multicolumn{6}{|l|}{ COMMELINACEAE (2) } \\
\hline Tradescantia zebrina Heynh. & HLA & ENT & $\mathrm{ZOO}$ & DIM & 4829 \\
\hline Tradescantia sp. & HLA & ENT & $\mathrm{ZOO}$ & DIM & - \\
\hline \multicolumn{6}{|l|}{ GESNERIACEAE (1) } \\
\hline Sinningia douglasii (Lindl.) Chautems & HLV & ORN & AUT & DIM & 3655 \\
\hline \multicolumn{6}{|l|}{ MORACEAE (1) } \\
\hline Ficus adhatodifolia Schott ex Spreng. & HMP & ENT & $\mathrm{ZOO}$ & CAR & 4058 \\
\hline \multicolumn{6}{|l|}{ ORCHIDACEAE (23) } \\
\hline Acianthera aphthosa (Lindl.) Pridgeon \& M.W. Chase & HLV & ENT & ANE & DIM & 4187 \\
\hline Acianthera fenestrata (Barb.Rodr.) Pridgeon \& M.W. Chase & HLV & ENT & ANE & DIM & 4046 \\
\hline Acianthera violaceomaculata (Hoehne) Pridgeon \& M.W. Chase & HLV & ENT & ANE & DIM & 4043 \\
\hline Acianthera pubescens (Lindl.) Pridgeon \& M.W. Chase & HLV & ENT & ANE & DIM & 3675 \\
\hline Anathallis dryadum (Schltr.) F. Barros & HLV & ENT & ANE & DIM & 4185 \\
\hline Anathallis linearifolia (Cogn.) Pridgeon \& M.W. Chase & HLV & ENT & ANE & DIM & 4186 \\
\hline Barbosella porschii (Kränzl.) Schltr. & HLV & ENT & ANE & DIM & 3657 \\
\hline Campylocentrum aromaticum Barb. Rodr. & HLV & ENT & ANE & DIM & 2717 \\
\hline Campylocentrum burchellii Cogn & HLV & ENT & ANE & DIM & 3611 \\
\hline Capanemia micromera Barb. Rodr. & HLV & ENT & ANE & DIM & 2712 \\
\hline Cattleya cernua (Lindl.) Van den Berg & HLV & ENT & ANE & DIM & 3649 \\
\hline Gomesa lietzei (Regel) M.W. Chase \& N.H. Willians & HLV & ENT & ANE & DIM & 4423 \\
\hline Gomesa longipes (Lindl. \& Praxt.) M.W. Chase \& N.H. Williams & HLV & ENT & ANE & DIM & 3679 \\
\hline
\end{tabular}


Tabela1. Continuação.

\begin{tabular}{|c|c|c|c|c|c|}
\hline FAMÍLIA / ESPÉCIE & $\mathrm{CE}$ & SP & SD & DP & $\mathrm{HCF}$ \\
\hline Lankesterella ceracifolia (Barb.Rodr.) Ames & HLV & ENT & ANE & DIM & 1254 \\
\hline Leptotes unicolor Barb. Rodr. & HLV & ENT & ANE & DIM & 4045 \\
\hline Maxillaria punctulata Klotzsch & HLV & ENT & ANE & DIM & 4404 \\
\hline Miltonia flavescens Lindl. & HLV & ENT & ANE & DIM & 3269 \\
\hline Octomeria sp. & HLV & ENT & ANE & DIM & 3676 \\
\hline Pleurothallis sp. 1 & HLV & ENT & ANE & DIM & 2801 \\
\hline Pleurothallis sp. 2 & HLV & ENT & ANE & DIM & 3656 \\
\hline Polystachya estrellensis Rchb. f. & HLV & ENT & ANE & DIM & 3650 \\
\hline Trichocentrum pumilum (Lindl.) M.W. Chase \& N.H. Willians & HLV & ENT & ANE & DIM & 3653 \\
\hline Zygostates alleniana Kränzl. & HLV & ENT & ANE & DIM & 3604 \\
\hline \multicolumn{6}{|l|}{ PIPERACEAE (5) } \\
\hline Peperomia catharinae Miq. & HLV & ANF & $\mathrm{ZOO}$ & VIS & 3600 \\
\hline Peperomia circinnata Link & HLV & ANF & $\mathrm{ZOO}$ & VIS & 4168 \\
\hline Peperomia tetraphylla (G. Forst.) Hook. \& Arn. & HLV & ANF & $\mathrm{ZOO}$ & VIS & 2802 \\
\hline Peperomia trineura Miq. & HLV & ANF & $\mathrm{ZOO}$ & VIS & 4056 \\
\hline Peperomia urocarpa Fisch. \& C.A. Mey. & HLV & ANF & $\mathrm{ZOO}$ & VIS & 3682 \\
\hline \multicolumn{6}{|l|}{ POLYPODIACEAE (8) } \\
\hline Campyloneurum nitidum (Kaulf.) C. Presl & HLV & - & ANE & DIM & 3651 \\
\hline Microgramma squamulosa (Kaulf.) de la Sota & HLV & - & ANE & DIM & 2787 \\
\hline Niphidium crassifolium (L.) Lellinger & HLV & - & ANE & DIM & 3678 \\
\hline Pecluma pectinatiformis (Lindm.) M.G. Price & HLV & - & ANE & DIM & 3605 \\
\hline Pecluma sicca (Lindm) M.G. Price & HLV & - & ANE & DIM & 2811 \\
\hline Pleopeltis angusta Humb. \& Bonpl. ex Willd. & HLV & - & ANE & DIM & 2718 \\
\hline Pleopeltis squalida (Vell.) de la Sota & HLV & - & ANE & DIM & 3273 \\
\hline Polypodium hirsutissimum Raddi & HLV & - & ANE & DIM & 3601 \\
\hline \multicolumn{6}{|l|}{ RUBIACEAE (1) } \\
\hline Mitracarpus hirtus (L.) DC. & HLA & ENT & $\mathrm{ZOO}$ & IND & 4050 \\
\hline \multicolumn{6}{|l|}{ URTICACEAE (2) } \\
\hline Cecropia pachystachya Trécul & HLA & ENT & $\mathrm{ZOO}$ & IND & 5469 \\
\hline Urera baccifera (L.) Gaudich. ex Wedd. & HLA & ANF & ANE & CAR & 4699 \\
\hline \multicolumn{6}{|l|}{ VITTARIACEAE (1) } \\
\hline Vittaria lineata (L.) Sm. & HLV & - & ANE & DIM & 4055 \\
\hline
\end{tabular}

esteve presente em $31 \%$ das espécies, com destaque para as pertencentes às famílias Cactaceae e Piperaceae. Segundo Fischer \& Araujo (1995), as espécies anemocóricas tendem a habitar a copa do hospedeiro em busca de zonas mais altas, enquanto que as espécies zoocóricas ocupam estratos de alturas mais baixas. Sinningia douglasii foi a única espécie considerada autocórica.

Sobre a distribuição vertical dos epífitos nos forófitos (Tab. 2), 29 espécies ocorreram no fuste inferior, a maioria pertencente às famílias Cactaceae, Piperaceae, Polypodiaceae e algumas espécies do gênero Tillandsia (Bromeliaceae). Também foi constatado que 39 espécies ocorreram no fuste superior, sendo que Miltonia flavescens ocorreu com maior freqüência nos intervalos de três a cinco metros. Na copa foi registrada a ocorrência de 37 espécies, a maioria da família Orchidaceae e o gênero Billbergia (Bromeliaceae).

Com relação às categorias ecológicas, 53 espécies foram classificadas como holoepífitas verdadeiras (espécies de Orchidaceae, Bromeliaceae, Polypodiaceae, Piperaceae e a maioria das Cactaceae); Aechmea distichantha (Bromeliaceae) foi considerada holoepífita facultativa, pois pode ser encontrada em hábito epífitico e terrícola; e cinco espécies foram consideradas como holoepífitas acidentais, onde o gênero Tradescantia foi representado por duas espécies. Ficus adhatodifolia (Moraceae) foi a única hemiepífita primária registrada e Philodendron bipinnatifidum (Araceae) a única hemiepífita secundária. 


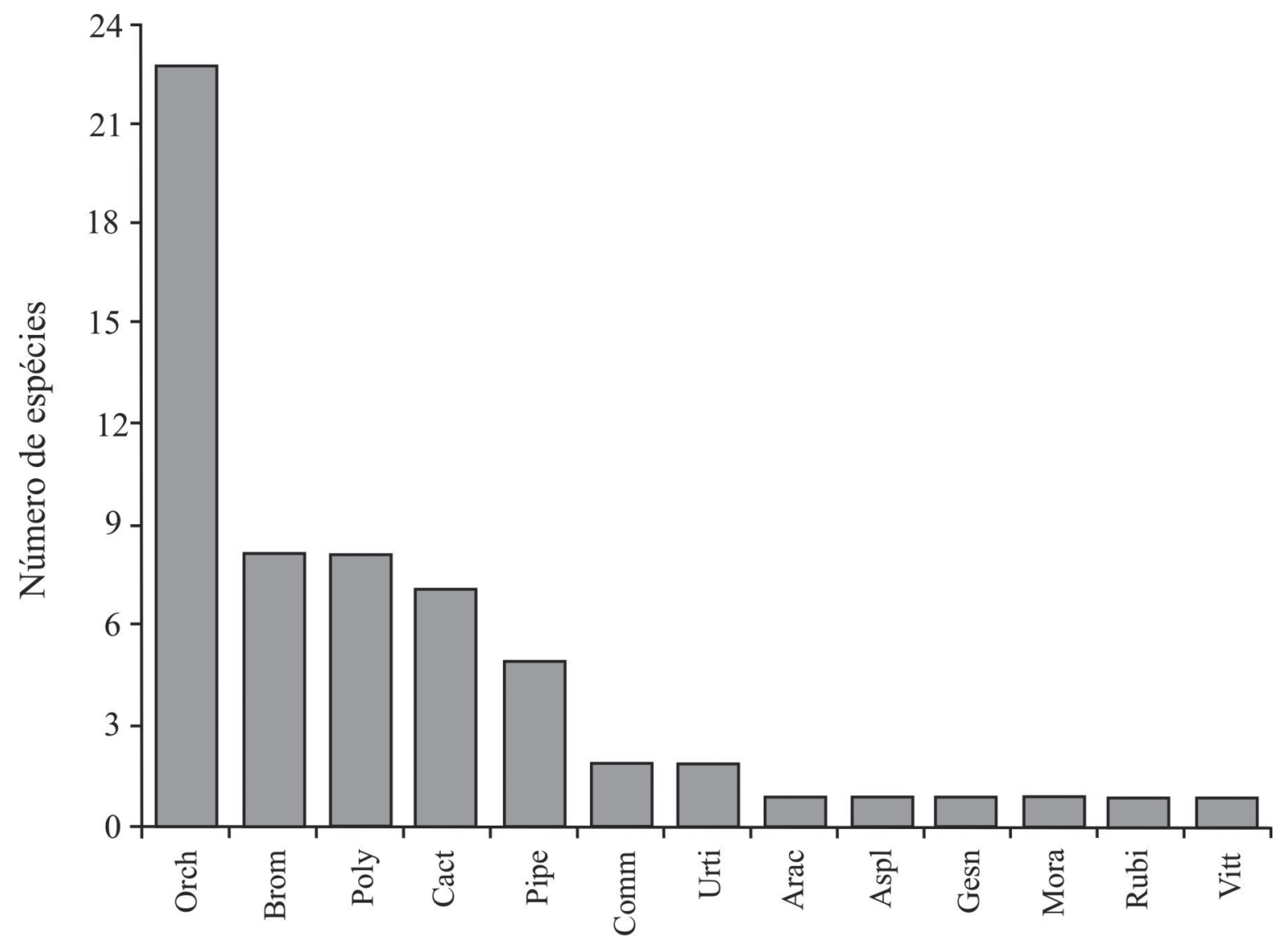

Figura 2. Número de espécies epifíticas por família na área florestal da Capela do Calvário em Campo Mourão, PR. Orch (Orchidaceae), Brom (Bromeliaceae), Poly (Polypodiaceae), Cact (Cactaceae), Pipe (Piperaceae), Comm (Commelinaceae), Urti (Urticaceae), Arac (Araceae), Aspl (Aspleniaceae), Gesn (Gesneriaceae), Mora (Moraceae), Rubi (Rubiaceae), Vitt (Vittariaceae).

Para avaliação da diversidade foi utilizado o índice de Shannon ( $\left.\mathrm{H}^{\prime}\right)$ onde o valor estimado foi de 3,175 e a equabilidade de Pielou (J) igual a 0,863 . Alguns estudos correlatos realizados no sul do Brasil apresentam resultados semelhantes aos encontrados neste estudo, considerando também o número de espécies (Tab. 3). De acordo com Giongo \& Waechter (2004), as áreas mais ricas estão situadas ao norte e apresentam índices de diversidade mais elevados por possuírem influência tropical.

Por meio dos parâmetros fitossociológicos das epífitas amostradas, podemos observar que Microgramma squamulosa foi a espécie mais importante, com valor de importância epifítico superior a 50\% na área de vegetação de interflúvio (Tab. 4 -5). O táxon Pleopeltis angusta ocupou a segunda posição (42,17\% de VIE) e Tillandsia loliaceae e T. recurvata ocuparam a terceira posição (ambas com 36,62\%). Já na área de vegetação ribeirinha as espécies mais importantes foram Microgramma squamulosa (35,48\%) e Pleopeltis angusta (29,36\%). Em relação à ocorrência de indivíduos epifíticos por espécie, a vegetação ribeirinha foi superior à vegetação de interflúvio, com exceção de Lepismium warmingianum e Leptotes unicolor com maior ocorrência de indivíduos na vegetação de interflúvio. Ficus adhatodifolia e Polypodium hirsutissimum apresentaram a mesma quantidade de indivíduos em ambas as áreas amostrais.
Considerando os valores de importância epifítico das duas áreas amostrais, podemos destacar 10 espécies que apresentaram valores superiores a $20 \%$. As famílias Bromeliaceae e Polypodiaceae foram as mais importantes, sendo representadas por quatro espécies cada. As outras duas são das famílias Cactaceae e Piperaceae.

Com relação à distribuição das espécies epifíticas sobre copas e fustes dos forófitos. Microgramma squamulosa destacou-se das demais com valores elevados nos dois segmentos, com 47 ocorrências na copa e 34 no fuste, além de ser a espécie com maior VIE (Fig. 3). Sobre a ocorrência nas copas, destacaram-se Pleopeltis angusta, Peperomia catharinae e Tillandsia tenuifolia com 30, 29 e 28 ocorrências respectivamente. No fuste o destaque foi para Pleopeltis angusta, com 32 ocorrências, e Pecluma sicca, com 29.

Das 61 espécies inventariadas na Capela do Calvário, 43 ocorreram nas áreas de amostragem, sendo que cinco em maior freqüência: Microgramma squamulosa, Pleopeltis angusta, Tillandsia loliacea, Tillandsia recurvata e Pecluma sicca. A vegetação ribeirinha apresentou 30 espécies e sete famílias e vegetação de interflúvio apresentou 34 espécies e nove famílias.

Além das espécies epifíticas também foram identificados os forófitos presentes nas áreas de amostragem (Tab. 6). O 
Tabela 2. Distribuição vertical das espécies epifíticas da Capela do Calvário em Campo Mourão, PR. Classificação da distribuição vertical: FI - fuste inferior, FS fuste superior e CP - copa.

\begin{tabular}{|c|c|c|c|c|c|c|c|}
\hline \multirow[t]{2}{*}{ Gênero/espécie } & \multicolumn{3}{|c|}{ Distribuição vertical } & \multirow[t]{2}{*}{ Gênero/espécie } & \multicolumn{3}{|c|}{ Distribuição vertical } \\
\hline & FI & FS & $\mathbf{C P}$ & & FI & FS & $\mathbf{C P}$ \\
\hline Philodendron bipinnatifidum & घ & घ & & Cattleya cernua & & & 曰 \\
\hline Asplenium scandicinum & - & & घ & Gomesa lietzei & & & - \\
\hline Aechmea distichantha & & घ & 曰 & Gomesa longipes & & & घ \\
\hline Billbergia alfonsi-joannis & & - & घ & Lankesterella ceracifolia & & & - \\
\hline Billbergia nutans & - & - & घ & Leptotes unicolor & & 口 & - \\
\hline Tillandsia loliacea & 匹 & - & 曰 & Maxillaria punctulata & & & 曰 \\
\hline Tillandsia meridionalis & - & - & & Miltonia flavescens & & - & 曰 \\
\hline Tillandsia recurvata & - & घ & & Octomeria sp. & & & घ \\
\hline Tillandsia tenuifolia & - & - & & Pleurothallis sp. 1 & & & घ \\
\hline Tillandsia tricholepis & - & - & & Pleurothallis sp. 2 & & & 曰 \\
\hline Cereus hildmannianus & & & 曰 & Polystachya estrellensis & & & घ \\
\hline Epiphyllum phyllanthus & - & - & & Trichocentrum pumilum & - & 口 & \\
\hline Lepismium crussiforme & - & - & 曰 & Zygostates alleniana & & & 曰 \\
\hline Lepismium lumbricoides & घ & घ & घ & Peperomia catharinae & $\square$ & घ & घ \\
\hline Lepismium warmingianum & - & - & & Peperomia circinnata & घ & - & \\
\hline Rhipsalis cereuscula & - & $\square$ & & Peperomia tetraphylla & घ & घ & 曰 \\
\hline Rhipsalis floccosa & - & - & & Peperomia trineura & - & 曰 & 曰 \\
\hline Tradescantia zebrina & घ & - & & Peperomia urocarpa & $\square$ & घ & \\
\hline Tradescantia sp. & घ & - & & Campyloneurum nitidum & & घ & 曰 \\
\hline Sinningia douglasii & & घ & & Microgramma squamulosa & घ & घ & घ \\
\hline Ficus adhatodifolia & - & - & & Niphidium crassifolium & & & 曰 \\
\hline Acianthera aphthosa & & & घ & Pecluma pectinatiformis & & घ & \\
\hline Acianthera fenestrata & घ & & & Pecluma sicca & $\square$ & घ & \\
\hline Acianthera violaceomaculata & & & 曰 & Pleopeltis angusta & - & घ & - \\
\hline Acianthera pubescens & & & 口 & Pleopeltis squalida & घ & - & \\
\hline Anathallis dryadum & & & - & Polypodium hirsutissimum & & - & घ \\
\hline Anathallis linearifolia & & & घ & Mitracarpus hirtus & & 口 & \\
\hline Barbosella porschii & & & - & Cecropia pachystachya & & घ & \\
\hline Campylocentrum aromaticum & & घ & 曰 & Urera baccifera & & & घ \\
\hline Campylocentrum burchellii & & & 曰 & Vittaria lineata & & घ & \\
\hline Capanemia micromera & $\mathbf{\square}$ & घ & & & & & \\
\hline
\end{tabular}

maior número de plantas epifíticas encontrado em um mesmo forófito foi de 38 indivíduos sobre Cordia americana (Boraginaceae), a maior riqueza específica em um único forófito foi 18, encontrada em Sebastiania commersoniana (Euphorbiaceae). Outros forófitos apresentaram números relativamente baixos quanto à quantidade de amostras, como em Araucaria angustifolia, Campomanesia xanthocarpa, Chrysophyllum gonocarpum, Eugenia uniflora e Parapiptadenia rigida. Também foi constatada a inexistência de epífitos em alguns forófitos com troncos lisos considerados impróprios para o suporte das espécies: Cecropia pachystachya, Eucalyptus sp., Euterpe edulis e Syagrus romanzoffiana.
Algumas espécies tiveram sua ocorrência restrita a apenas um forófito, como em Gesneriaceae (Sinningia douglasii) e muitas Orchidaceae (Acianthera aphthosa, Acianthera violaceomaculata, Anathallis linearifolia, Cattleya cernua, Gomesa longipes, Pleurothallis sp. 2, Polystachya estrellensis e Zygostates alleniana). Já Acianthera pubescens, Anathallis dryadum e Pleurothallis sp. 1 foram encontradas em dois forófitos e Octomeria sp. teve seu registro em três forófitos.

Cattleya cernua (Orchidaceae) está incluída na Lista Vermelha de Espécies Ameaçadas de Extinção no estado do Paraná, na categoria em "perigo de extinção" (Hatschbach \& Ziller 1995). 
Tabela 3. Riqueza e diversidade de epífitos vasculares em diversos estudos realizados nos Estados do Paraná e Rio Grande do Sul (Brasil). (S) N de espécies, (H’) índice de diversidade de Shannon e (J) equabilidade de Pielou.

\begin{tabular}{lcccl}
\hline Local & S & H' & J & Referências \\
\hline Faxinal/Torres, RS & 93 & 4,049 & 0,89 & Waechter (1992) \\
Ilha do Mel, PR & 77 & 3,609 & 0,784 & Kersten \& Silva (2001) \\
Eldorado do Sul, RS & 50 & 3,434 & 0,878 & Giongo \& Waechter (2004) \\
Campo Mourão, PR & 61 & 3,175 & 0,863 & Presente estudo \\
Osório, RS & 53 & 2,990 & 0,87 & Waechter (1998) \\
Araucária, PR & 51 & 2,706 & 0,767 & Kersten \& Silva (2002) \\
Maringá, PR & 29 & 1,106 & 0,824 & Dettke et al. (2008) \\
\hline
\end{tabular}

Tabela 4. Parâmetros fitossociológicos dos epífitos. N - número de indivíduos; DR - densidade relativa (\%); NI - número de indivíduos arbóreos em que ocorre; FAI - freqüência absoluta sobre indivíduos arbóreos; FRI - freqüência relativa sobre indivíduos arbóreos (\%); NS - número de espécies arbóreas em que ocorre; FAS - freqüência absoluta sobre espécies de árvores e FRS - freqüência relativa sobre espécies de árvores (\%).

\begin{tabular}{|c|c|c|c|c|c|c|c|c|}
\hline Espécie & $\mathrm{N}$ & $\mathrm{DR}$ & $\mathrm{NI}$ & FAI & FRI & NS & FAS & FRS \\
\hline Microgramma squamulosa & 81 & 11,98 & 66 & 33,83 & 14,29 & 24 & 25,72 & 9,52 \\
\hline Pleopeltis angusta & 62 & 9,17 & 49 & 24,27 & 10,61 & 18 & 22,93 & 7,14 \\
\hline Pecluma sicca & 44 & 6,50 & 37 & 17,64 & 8,01 & 11 & 11,14 & 4,37 \\
\hline Tillandsia tenuifolia & 42 & 6,21 & 29 & 14,11 & 6,28 & 12 & 13,98 & 4,76 \\
\hline Peperomia catharinae & 39 & 5,77 & 18 & 9,02 & 3,90 & 13 & 16,36 & 5,16 \\
\hline Lepismium crussiforme & 36 & 5,33 & 12 & 6,07 & 2,60 & 6 & 6,68 & 2,38 \\
\hline Tillandsia loliacea & 33 & 4,88 & 16 & 7,18 & 3,46 & 11 & 11,14 & 4,37 \\
\hline Tillandsia recurvata & 33 & 4,88 & 14 & 6,76 & 3,03 & 9 & 8,73 & 3,57 \\
\hline Pleopeltis squalida & 30 & 4,44 & 16 & 7,18 & 3,46 & 11 & 11,14 & 4,37 \\
\hline Tillandsia tricholepis & 26 & 3,85 & 18 & 7,49 & 3,90 & 10 & 9,44 & 3,97 \\
\hline Rhipsalis cereuscula & 25 & 3,70 & 16 & 7,18 & 3,46 & 10 & 9,44 & 3,97 \\
\hline Trichocentrum pumilum & 22 & 3,25 & 15 & 6,87 & 3,25 & 12 & 13,98 & 4,76 \\
\hline Miltonia flavescens & 20 & 2,96 & 11 & 4,93 & 2,38 & 10 & 9,44 & 3,97 \\
\hline Peperomia tetraphylla & 19 & 2,81 & 9 & 4,22 & 1,95 & 6 & 6,68 & 2,38 \\
\hline Billbergia nutans & 18 & 2,66 & 14 & 6,76 & 3,03 & 7 & 7,04 & 2,78 \\
\hline Tillandsia meridionalis & 17 & 2,51 & 13 & 5,81 & 2,81 & 8 & 7,65 & 3,17 \\
\hline Epiphyllum phyllanthus & 14 & 2,07 & 13 & 5,81 & 2,81 & 6 & 6,68 & 2,38 \\
\hline Lepismium lumbricoides & 12 & 1,78 & 11 & 4,93 & 2,38 & 9 & 8,73 & 3,57 \\
\hline Aechmea distichantha & 12 & 1,78 & 10 & 4,55 & 2,16 & 6 & 6,68 & 2,38 \\
\hline Rhipsalis floccosa & 12 & 1,78 & 11 & 4,93 & 2,38 & 4 & 5,37 & 1,59 \\
\hline Peperomia trineura & 11 & 1,63 & 8 & 3,84 & 1,73 & 6 & 6,68 & 2,38 \\
\hline Lepismium warmingianum & 10 & 1,48 & 7 & 3,49 & 1,52 & 5 & 6,11 & 1,98 \\
\hline Philodendron bipinnatifidum & 8 & 1,18 & 8 & 3,84 & 1,73 & 4 & 5,37 & 1,59 \\
\hline Polypodium hirsutissimum & 8 & 1,18 & 7 & 3,49 & 1,52 & 5 & 6,11 & 1,98 \\
\hline Campylocentrum burchellii & 7 & 1,04 & 4 & 2,96 & 0,87 & 2 & 3,46 & 0,79 \\
\hline Capanemia micromera & 6 & 0,89 & 5 & 2,67 & 1,08 & 3 & 3,81 & 1,19 \\
\hline Leptotes unicolor & 5 & 0,74 & 3 & 2,17 & 0,65 & 3 & 3,81 & 1,19 \\
\hline Billbergia alfonsi-joannis & 4 & 0,59 & 3 & 2,17 & 0,65 & 2 & 3,46 & 0,79 \\
\hline Asplenium scandicinum & 2 & 0,30 & 2 & 1,63 & 0,43 & 2 & 3,46 & 0,79 \\
\hline Barbosella porschii & 2 & 0,30 & 1 & 0,88 & 0,22 & 1 & 2,66 & 0,40 \\
\hline Campyloneurum nitidum & 2 & 0,30 & 2 & 1,63 & 0,43 & 2 & 3,46 & 0,79 \\
\hline Lankesterella ceracifolia & 2 & 0,30 & 2 & 1,63 & 0,43 & 2 & 3,46 & 0,79 \\
\hline
\end{tabular}


Tabela 4. Continuação.

\begin{tabular}{|c|c|c|c|c|c|c|c|c|}
\hline Espécie & $\mathrm{N}$ & DR & NI & FAI & FRI & NS & FAS & FRS \\
\hline Ficus adhatodifolia & 2 & 0,30 & 2 & 1,63 & 0,43 & 2 & 3,46 & 0,79 \\
\hline Campylocentrum aromaticum & 1 & 0,15 & 1 & 0,88 & 0,22 & 1 & 2,66 & 0,40 \\
\hline Cecropia pachystachya & 1 & 0,15 & 1 & 0,88 & 0,22 & 1 & 2,66 & 0,40 \\
\hline Cereus hildmannianus & 1 & 0,15 & 1 & 0,88 & 0,22 & 1 & 2,66 & 0,40 \\
\hline Niphidium crassifolium & 1 & 0,15 & 1 & 0,88 & 0,22 & 1 & 2,66 & 0,40 \\
\hline Gomesa longipes & 1 & 0,15 & 1 & 0,88 & 0,22 & 1 & 2,66 & 0,40 \\
\hline Acianthera aphthosa & 1 & 0,15 & 1 & 0,88 & 0,22 & 1 & 2,66 & 0,40 \\
\hline Pecluma pectinatiforme & 1 & 0,15 & 1 & 0,88 & 0,22 & 1 & 2,66 & 0,40 \\
\hline Tradescantia zebrina & 1 & 0,15 & 1 & 0,88 & 0,22 & 1 & 2,66 & 0,40 \\
\hline Tradescantia sp. & 1 & 0,15 & 1 & 0,88 & 0,22 & 1 & 2,66 & 0,40 \\
\hline Zygostates alleniana & 1 & 0,15 & 1 & 0,88 & 0,22 & 1 & 2,66 & 0,40 \\
\hline TOTAL & 676 & 100 & 462 & 230,37 & 100 & 252 & 297,05 & 100 \\
\hline
\end{tabular}

Tabela 5. Parâmetros fitossociológicos dos epífitos por área florestal. FA - freqüência absoluta, FR - freqüência relativa (\%), VIE - valor de importância epifítico e (-) espécie que não ocorreu na área.

\begin{tabular}{|c|c|c|c|c|c|c|}
\hline \multirow[b]{2}{*}{ Espécie } & \multicolumn{3}{|c|}{ Vegetação ribeirinha } & \multicolumn{3}{|c|}{ Vegetação de interflúvio } \\
\hline & FA & FR & VIE & FA & FR & VIE \\
\hline Microgramma squamulosa & 29 & 12,95 & 35,48 & 52 & 11,40 & 57,70 \\
\hline Pleopeltis angusta & 24 & 10,71 & 29,36 & 38 & 8,33 & 42,17 \\
\hline Pecluma sicca & 18 & 8,04 & 22,02 & 26 & 5,70 & 28,85 \\
\hline Tillandsia tenuifolia & 19 & 8,48 & 23,24 & 23 & 5,04 & 25,52 \\
\hline Peperomia catharinae & 18 & 8,04 & 22,02 & 21 & 4,61 & 23,31 \\
\hline Lepismium crussiforme & 18 & 8,04 & 22,02 & 22 & 4,82 & 24,41 \\
\hline Tillandsia loliacea & - & - & - & 33 & 7,24 & 36,62 \\
\hline Tillandsia recurvata & - & - & - & 33 & 7,24 & 36,62 \\
\hline Pleopeltis squalida & 11 & 4,91 & 13,46 & 19 & 4,17 & 21,09 \\
\hline Tillandsia tricholepis & - & - & - & 26 & 5,70 & 28,85 \\
\hline Rhipsalis cereuscula & 11 & 4,91 & 13,46 & 14 & 3,07 & 15,54 \\
\hline Trichocentrum pumilum & 9 & 4,02 & 11,01 & 13 & 2,85 & 14,43 \\
\hline Miltonia flavescens & 5 & 2,23 & 6,12 & 15 & 3,29 & 16,65 \\
\hline Peperomia tetraphylla & 7 & 3,13 & 8,57 & 12 & 2,63 & 13,32 \\
\hline Billbergia nutans & 6 & 2,68 & 7,34 & 12 & 2,63 & 13,32 \\
\hline Tillandsia meridionalis & 7 & 3,13 & 8,57 & 10 & 2,19 & 11,10 \\
\hline Epiphyllum phyllanthus & 5 & 2,23 & 6,12 & 9 & 1,97 & 9,99 \\
\hline Lepismium lumbricoides & - & - & - & 12 & 2,63 & 13,32 \\
\hline Aechmea distichantha & 4 & 1,79 & 4,90 & 8 & 1,75 & 8,88 \\
\hline Rhipsalis floccosa & - & - & - & 12 & 2,63 & 13,32 \\
\hline Peperomia trineura & - & - & - & 11 & 2,41 & 12,21 \\
\hline Lepismium warmingianum & 6 & 2,68 & 7,34 & 4 & 0,88 & 4,44 \\
\hline Philodendron bipinnatifidum & 2 & 0,89 & 2,45 & 6 & 1,32 & 6,66 \\
\hline Polypodium hirsutissimum & 4 & 1,79 & 4,90 & 4 & 0,88 & 4,44 \\
\hline Campylocentrum burchellii & 3 & 1,34 & 3,67 & 4 & 0,88 & 4,44 \\
\hline Capanemia micromera & - & - & - & 6 & 1,32 & 6,66 \\
\hline Leptotes unicolor & 4 & 1,79 & 4,90 & 1 & 0,22 & 1,11 \\
\hline
\end{tabular}


Tabela 5. Continuação.

\begin{tabular}{|c|c|c|c|c|c|c|}
\hline \multirow[b]{2}{*}{ Espécie } & \multicolumn{3}{|c|}{ Vegetação ribeirinha } & \multicolumn{3}{|c|}{ Vegetação de interflúvio } \\
\hline & FA & FR & VIE & FA & FR & VIE \\
\hline Billbergia alfonsi-joannis & - & - & - & 4 & 0,88 & 4,44 \\
\hline Asplenium scandicinum & 2 & 0,89 & 2,45 & - & - & - \\
\hline Barbosella porschii & 2 & 0,89 & 2,45 & - & - & - \\
\hline Campyloneurom nitidum & 2 & 0,89 & 2,45 & - & - & - \\
\hline Lankesterella ceracifolia & 2 & 0,89 & 2,45 & - & - & - \\
\hline Ficus adhatodifolia & 1 & 0,45 & 1,23 & 1 & 0,22 & 1,11 \\
\hline Campylocentrum aromaticum & 1 & 0,45 & 1,23 & - & - & - \\
\hline Cecropia pachystachya & 1 & 0,45 & 1,23 & - & - & - \\
\hline Cereus hildmannianus & - & - & - & 1 & 0,22 & 1,11 \\
\hline Niphidium crassifolium & 1 & 0,45 & 1,23 & - & - & - \\
\hline Gomesa longipes & - & - & - & 1 & 0,22 & 1,11 \\
\hline Acianthera aphthosa & 1 & 0,45 & 1,23 & - & - & - \\
\hline Pecluma pectinatiforme & 1 & 0,45 & 1,23 & - & - & - \\
\hline Tradescantia zebrina & - & - & - & 1 & 0,22 & 1,11 \\
\hline Tradescantia sp. & - & - & - & 1 & 0,22 & 1,11 \\
\hline Zygostates alleniana & - & - & - & 1 & 0,22 & 1,11 \\
\hline TOTAL & 224 & 100 & 274,13 & 456 & 100 & 506,07 \\
\hline
\end{tabular}

Segundo Miller \& Warren (1996), o gênero Cattleya possui cerca de 70 espécies e inúmeras variedades havendo mais de 100.000 híbridos. Cattleya cernua é bem diferente das outras porque geralmente é multiflora. Todas as espécies nativas do Brasil habitam quase que exclusivamente em florestas primárias, em geral acima de 1.200 metros de altitude até o pico das montanhas mais altas. Na realidade, é quase consenso em discussão que se espécies deste gênero estiverem presentes nas árvores, trata-se de uma floresta original ou remanescente da floresta primitiva.

Outra espécie que também está ameaçada de extinção é Billbergia alfonsi-joannis (Bromeliaceae), incluída na "Lista Oficial de Espécies da Flora Brasileira Ameaçada de Extinção" (Ministério do Meio Ambiente 2008). A espécie está enquadrada na categoria "em perigo" nos estados do Espírito Santo e Santa Catarina, porém, foi encontrada com freqüência na área de estudo.

Também foram notadas diferenças na composição florística da comunidade de epífitos de acordo com os estágios sucessionais: a Vegetação ribeirinha apresentou maior número de plantas e menor riqueza; já na Vegetação de interflúvio a riqueza foi maior, porém o número de indivíduos menor.

Algumas epífitas investigadas são diagnósticas de florestas secundárias, como Campylocentrum burchellii, Leptotes unicolor, Microgramma squamulosa, Peperomia catharinae, Pleopeltis angusta, Polypodium hirsutissimum, Tillandsia recurvata e Tillandsia tenuifolia, todas consideradas espécies pioneiras e observadas nas duas áreas de estudo. Outras epífitas foram encontradas em locais mais bem con- servados com presença de árvores remanescentes, como, Acianthera aphthosa, A. fenestrata, A. violaceomaculata, Anathallis linearifolia, Asplenium scandicinum, Billbergia alfonsi-joannis, B. nutans, Cattleya cernua, Maxillaria punctulata, Niphidium crassifolium, Rhipsalis floccosa, Sinningia douglasii e Zygostates alleniana, mais freqüentes na floresta primária.

O estudo sobre a vegetação do estado do Paraná realizado por Maack (1981) apresenta a riqueza da comunidade de epífitas vasculares na Floresta Ombrófila Mista, no qual Bromeliaceae, Polypodiaceae (lato sensu), Orchidaceae, Hymenophyllaceae e Araceae foram citadas como as famílias com maior riqueza específica. Na Capela do Calvário, Bromeliaceae, Polypodiaceae e Orchidaceae, também estão entre as mais abundantes, mas Hymenophyllaceae, também esperada para este tipo de formação florestal, não foi encontrada. Porém, outros estudos realizados na região de Campo Mourão registraram a presença de Trichomanes radicans $\mathrm{Sw}$. (Hymenophyllaceae) em áreas florestais dos municípios de Luiziana-PR (localizado a $30 \mathrm{Km}$ de Campo Mourão) e Corumbataí do Sul-PR (localizado a $50 \mathrm{Km}$ de Campo Mourão).

Os resultados obtidos mostram um total de 13 famílias, onde apenas cinco delas alcançaram $83 \%$ do total de espécies (Bromeliaceae, Cactaceae, Orchidaceae, Piperaceae e Polypodiaceae) e as pteridófitas contribuíram com 10 espécies. Estes dados podem ser comparados ao estudo de Borgo et al. (2002), realizado no município de Fênix, que contempla a mesma microrregião de Campo Mourão. Neste 


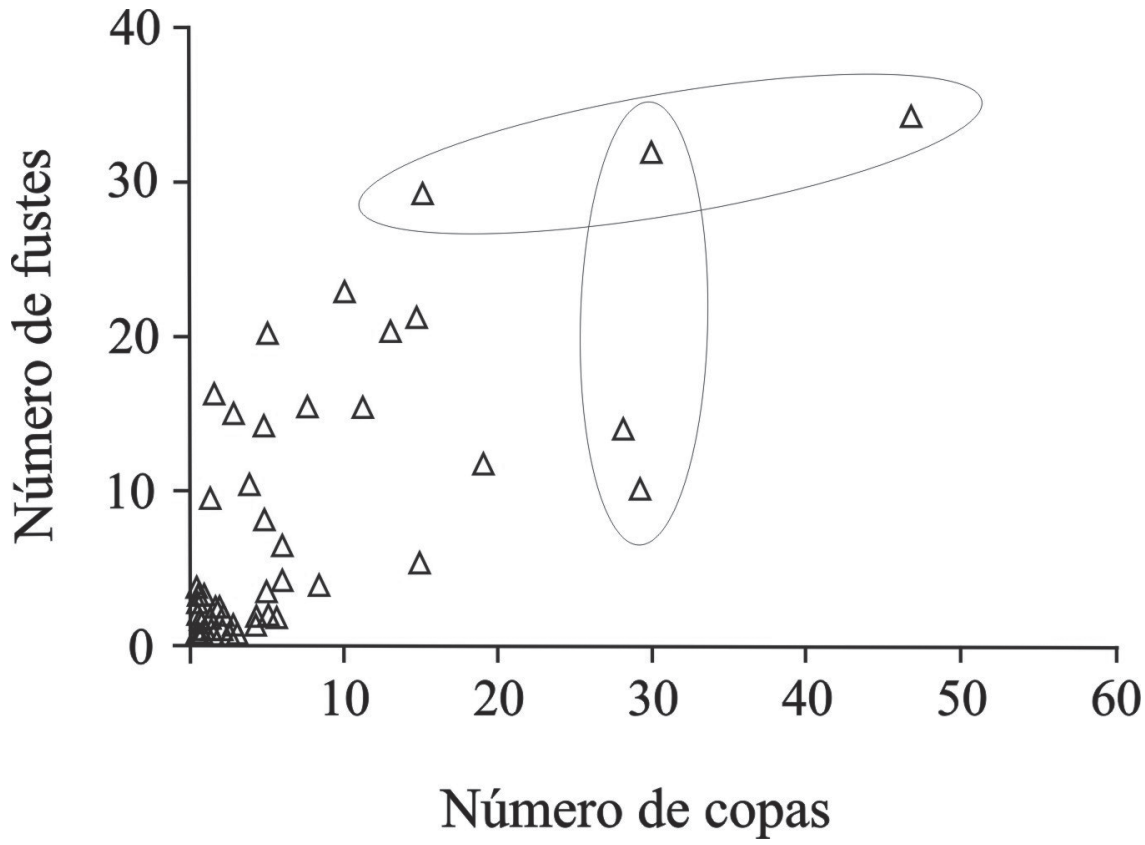

Figura 3. Distribuição das epífitas vasculares sobre copas e fustes dos forófitos da Capela do Calvário em Campo Mourão, PR. O círculo horizontal destaca as maiores ocorrências de espécies epifíticas no fuste e o círculo vertical as maiores ocorrências na copa.

Tabela 6. Componente arbóreo encontrado na área de amostragem da Capela do Calvário em Campo Mourão, PR. (S) № de forófitos; Md. ind. - média de ocorrência dos indivíduos epifíticos; Md. spp. - média de espécies epifíticas; DP - desvio-padrão; CV \% - coeficiente de variação.

\begin{tabular}{|c|c|c|c|c|c|c|c|c|c|}
\hline FAMÍLIA/ ESPÉCIE & $\begin{array}{c}\text { Formação } \\
\text { florestal }\end{array}$ & $\begin{array}{c}\text { Área } \\
\text { amostral }\end{array}$ & S & $\begin{array}{l}\text { Md. } \\
\text { ind. }\end{array}$ & $\mathrm{DP}$ & $\mathrm{CV} \%$ & $\begin{array}{l}\text { Md. } \\
\text { spp. }\end{array}$ & DP & $\mathrm{CV} \%$ \\
\hline \multicolumn{10}{|l|}{ ANACARDIACEAE } \\
\hline Schinus terebinthifolia Raddi & FOM & VRP & 2 & 5 & 2,12 & 42,20 & 2 & 0,70 & 35 \\
\hline \multicolumn{10}{|l|}{ APOCYNACEAE } \\
\hline Aspidosperma polyneuron Müll. Arg. & FES & VRP/VRM & 4 & 11 & 3,50 & 31,81 & 6 & 2,21 & 36,83 \\
\hline \multicolumn{10}{|l|}{ AQUIFOLIACEAE } \\
\hline Ilex paraguariensis A. St.-Hil. & FOM/FES & VRM & 2 & 4 & 2,12 & 53 & 2 & 0,70 & 35 \\
\hline \multicolumn{10}{|l|}{ ARAUCARIACEAE } \\
\hline Araucaria angustifolia (Bertol.) Kuntze & FOM & VRP & 5 & 9 & 3,70 & 41,11 & 3 & 0,89 & 29,66 \\
\hline \multicolumn{10}{|l|}{ ARECACEAE } \\
\hline Euterpe edulis Mart. & FES & VRP & 1 & - & - & - & - & - & - \\
\hline Syagrus romanzoffiana (Cham.) Glassman & $\mathrm{FOM} / \mathrm{FES}$ & VRP & 2 & - & - & - & - & - & - \\
\hline \multicolumn{10}{|l|}{ BIGNONIACEAE } \\
\hline Jacaranda puberula Cham. & FOM & VRP/VRM & 3 & 16 & 5,85 & 36,56 & 9 & 2,51 & 27,88 \\
\hline Tabebuia heptaphylla (Vell.) Toledo & FES & VRP/VRM & 2 & 5 & 1,41 & 28,20 & 2 & 0,70 & 35 \\
\hline \multicolumn{10}{|l|}{ BORAGINACEAE } \\
\hline Cordia americana (L.) Gottschling \& J.S. Mill. & $\mathrm{FOM} / \mathrm{FES}$ & VRP/VRM & 3 & 29 & 9,50 & 32,75 & 12 & 3,00 & 25 \\
\hline Cordia trichotoma (Vell.) Arráb. ex Steud. & FES & VRP/VRM & 1 & 7 & - & - & 4 & - & - \\
\hline \multicolumn{10}{|l|}{ CANNABACEAE } \\
\hline Celtis iguanaea (Jacq.) Sarg. & FOM/FES & VRM & 3 & 15 & 5,56 & 37,06 & 10 & 3,60 & 36 \\
\hline Trema micrantha (L.) Blume & FES & VRP & 2 & 6 & 3,53 & 58,83 & 2 & 0,70 & 35 \\
\hline
\end{tabular}


Tabela 6. Continuação.

\begin{tabular}{|c|c|c|c|c|c|c|c|c|c|}
\hline FAMÍLIA/ ESPÉCIE & $\begin{array}{c}\text { Formação } \\
\text { florestal }\end{array}$ & $\begin{array}{c}\text { Área } \\
\text { amostral }\end{array}$ & $\mathrm{S}$ & $\begin{array}{l}\text { Md. } \\
\text { ind. }\end{array}$ & $\mathrm{DP}$ & $\mathrm{CV} \%$ & $\begin{array}{l}\text { Md. } \\
\text { spp. }\end{array}$ & DP & $\mathrm{CV} \%$ \\
\hline \multicolumn{10}{|l|}{ EUPHORBIACEAE } \\
\hline Croton floribundus Spreng. & FES & VRP/ VRM & 4 & 17 & 4,83 & 28,41 & 6 & 1,63 & 27,16 \\
\hline Sebastiania commersoniana (Baill.) L.B. Sm. \& Downs & FOM/FES & VRP/ VRM & 6 & 26 & 6,21 & 23,88 & 17 & 4,13 & 24,29 \\
\hline \multicolumn{10}{|l|}{ FABACEAE } \\
\hline Caesalpinia peltophoroides Benth. & EXÓTICA & VRM & 2 & 5 & 2,82 & 56,40 & 2 & 0,70 & 35 \\
\hline Bauhinia variegata $\mathrm{L}$. & EXÓTICA & VRM & 1 & 3 & - & - & 1 & - & - \\
\hline Parapiptadenia rigida (Benth.) Brenan & FES & VRM & 4 & 8 & 2,21 & 27,62 & 3 & 0,82 & 27,33 \\
\hline \multicolumn{10}{|l|}{ LAURACEAE } \\
\hline Nectandra grandiflora Ness \& C. Mart. ex Ness & FOM/FES & VRP & 4 & 9 & 2,38 & 26,44 & 4 & 0,96 & 24 \\
\hline Nectandra lanceolata Nees & FOM/FES & VRP & 3 & 11 & 2,51 & 22,81 & 5 & 1,52 & 30,40 \\
\hline \multicolumn{10}{|l|}{ MALPIGHIACEAE } \\
\hline Malpighia glabra L. & EXÓTICA & VRM & 1 & 1 & - & - & 1 & - & - \\
\hline \multicolumn{10}{|l|}{ MALVACEAE } \\
\hline Ceiba speciosa (A. St.-Hil.) Ravenna & FOM/FES & VRP/ VRM & 2 & 6 & 0,70 & 11,66 & 2 & 0,70 & 35 \\
\hline Luehea divaricata Mart. & FOM/FES & VRP/ VRM & 1 & 1 & - & - & 1 & - & - \\
\hline \multicolumn{10}{|l|}{ MELIACEAE } \\
\hline Cedrela fissilis Vell. & FOM/FES & VRP/ VRM & 3 & 13 & 5,13 & 39,46 & 5 & 1,15 & 23 \\
\hline \multicolumn{10}{|l|}{ MORACEAE } \\
\hline Ficus sp. 1 & - & VRM & 2 & 19 & 7,07 & 37,21 & 10 & 2,12 & 21,20 \\
\hline Ficus sp. 2 & - & VRM & 3 & 14 & 4,58 & 32,71 & 7 & 2,08 & 29,71 \\
\hline \multicolumn{10}{|l|}{ MYRTACEAE } \\
\hline Campomanesia xanthocarpa O. Berg & FOM/FES & VRM & 2 & 5 & 1,41 & 28,20 & 1 & - & - \\
\hline Eugenia uniflora L. & FOM/FES & VRM & 1 & 2 & - & - & 1 & - & - \\
\hline Eucalyptus sp. & EXÓTICA & VRM & 3 & - & - & - & - & - & - \\
\hline Plinia rivularis (Cambess.) Rotman & FOM/FES & VRP & 2 & 2 & 0,70 & 35 & 2 & 0,70 & 35 \\
\hline \multicolumn{10}{|l|}{ SAPOTACEAE } \\
\hline Chrysophyllum gonocarpum (Mart. \& Eichler ex Miq.) Engl. & FES & VRP & 1 & 8 & - & - & 6 & - & - \\
\hline Chrysophyllum marginatum (Hook. \& Arn.) Radlk. & FES & VRP & 2 & 13 & 4,24 & 32,61 & 5 & 1,41 & 28,20 \\
\hline \multicolumn{10}{|l|}{ SALICACEAE } \\
\hline Casearia sylvestris $\mathrm{Sw}$. & FOM/FES & VRP & 2 & 16 & 7,07 & 44,18 & 6 & 2,12 & 35,33 \\
\hline \multicolumn{10}{|l|}{ URTICACEAE } \\
\hline Cecropia pachystachya Trécul & FES & VRP & 1 & - & - & - & - & - & - \\
\hline
\end{tabular}

FOM - Floresta Ombrófila Mista; FES - Floresta Estacional Semidecidual; VRM - Vegetação remanescente; VRP - Vegetação ripária.

estudo foram constatadas nove famílias, sendo que $75 \%$ das espécies foram representadas por Cactaceae, Orchidaceae, Piperaceae e Polypodiaceae e as pteridófitas contribuíram com nove espécies.

A riqueza investigada neste trabalho segue o padrão encontrado em diversos estudos envolvendo epífitos vasculares, onde as espécies são agrupadas em poucas famílias e com destaque para Orchidaceae e Bromeliaceae como as mais ricas. O número de espécies encontrado foi superior a muitos estudos realizados em Floresta Estacional Semidecidual (Tab. 7). Em relação à riqueza, também foi bem similar ao estudo de Boelter \& Fonseca (2007), onde foram constatadas 62 espécies em uma Floresta Ombrófila Mista no Rio Grande do Sul. Porém, esta riqueza é considerada baixa se comparada com a maioria dos estudos realizados em Floresta Ombrófila Mista: Dittrich et al. (1999) com 74 
Tabela 7. Comparação entre estudos envolvendo epífitas vasculares na Floresta Estacional Semidecidual (FES) e Floresta Ombrófila Mista (FOM) nos estados do Paraná, Rio Grande do Sul e São Paulo.

\begin{tabular}{lcccl}
\hline Localidade & Formação florestal & Área (ha) & $\begin{array}{c}\mathrm{N}^{\circ} \text { de } \\
\text { espécies }\end{array}$ & Referências bibliográficas \\
\hline Bacia do Rio Iguaçu, Primeiro Planalto Paranaense & FOM & - & 114 & Kersten \& Kuniyoshi (2009) \\
Curitiba, PR & FOM & 97 & 96 & Borgo \& Silva (2003) \\
Parque Barigüi, Curitiba, PR & FOM & 50 & 74 & Dittrich et al. (1999) \\
Floresta Nacional de São Francisco de Paula, RS & FOM & - & 62 & Boelter \& Fonseca (2007) \\
Capela do Calvário, Campo Mourão, PR & FES e FOM & 30 & 61 & Presente estudo \\
Parque Nacional do Iguaçu, PR & FES e FOM & 17.000 & 56 & **Cervi \& Borgo (2007) \\
Araucária, PR & FOM & 8,6 & 51 & Kersten \& Silva (2002) \\
Campus II da UFPR, Curitiba, PR & FOM & 13,9 & 40 & Cervi \& Dombrowski (1985), Cervi et al. (1988) \\
Floresta Nacional de Passo Fundo, RS & FOM & - & 44 & Buzzato et al. (2008) \\
CUASO, São Paulo, SP & FES & 10,2 & 37 & Dislich \& Mantovani (1998) \\
PEVR, Fênix, PR & FES & 354 & 32 & Borgo et al. (2002) \\
Parque do Ingá, Maringá, PR & FES & 47,3 & 29 & Dettke et al. (2008) \\
Jaboticabal, SP & FES & - & 12 & *Pinto et al. (1995) \\
\hline
\end{tabular}

* Apenas Magnoliófitas **Levantamento preliminar

espécies, Borgo \& Silva (2003) com 96 espécies e Kersten \& Kuniyoshi (2009) com 114 espécies.

O levantamento preliminar realizado por Cervi \& Borgo (2007) no Parque Nacional do Iguaçu em Foz do Iguaçu, PR, apresentou grande similaridade com a área florestal da Capela do Calvário em relação aos tipos vegetacionais e a florística. O estudo foi desenvolvido numa área de Floresta Estacional Semidecidual e Floresta Ombrófila Mista, sendo esta restrita a um pequeno trecho do parque. Foram listadas 56 epífitas, sendo 20 delas também registradas para Capela do Calvário.

Apesar de não se tratar de um estudo voltado para a conservação e preservação de plantas, os resultados obtidos apresentam grande importância para fins de conservação e práticas de manejo florestal. As perturbações florestais resultam em impactos significativos sobre a comunidade de epífitas vasculares, podendo refletir nos processos ecológicos em que participam e também sobre a fauna que depende destas espécies para sua sobrevivência. É importante destacar que as epífitas são plantas vulneráveis à degradação ambiental e muitas espécies podem estar desaparecendo, ainda sem o conhecimento da ciência. Portanto, sugere-se o desenvolvimento de iniciativas objetivando a preservação destes locais, mesmo que sejam pequenos fragmentos, e até mesmo a reprodução de epífitas com intuito de amenizar os riscos de extinção.

\section{Agradecimentos}

A diretoria do Ministério Capela do Calvário por terem cedido á área para este estudo, aos professores Dr. Marcelo Galeazzi Caxambú e Dra . Débora Cristina de Souza pela orientação, aos amigos André Aparecido Machado e Ronaldo César Ferreira pelo apoio nas excursões, à equipe do Herbário da Universidade Tecnológica Federal do Paraná, campus Campo Mourão (HCF) e do Museu Botânico de Curitiba (MBM) pelo auxílio nas determinações.

\section{Referências Bibliográficas}

Benzing, D.H. 1990. Vascular epiphytes. Cambridge Cambridge University Press.

Benzing, 1995. Vascular epiphytes. Pp. 225-254. In: M. D. Lowman \& N. M. Nadkarni (eds.). Forest canopies. San Diego, Academic Press.

Boelter, C.R. \& Fonseca, C.R. 2007. Abundância, riqueza e composição de epífitos vasculares em Floresta com Araucária e monocultúras arbóreas. In: Anais do VIII Congresso de Ecologia do Brasil, Caxambú; MG.

Borgo, M.; Silva, S.M. \& Petean, M.P. 2002. Epífitos vasculares em um remanescente de floresta estacional semidecidual, município de Fênix, PR, Brasil. Acta Biológica Leopoldensia 24: 121-130.

Borgo, M. \& Silva, S.M. 2003. Epífitos vasculares em fragmentos de Floresta Ombrófila Mista, Curitiba, Paraná, Brasil. Revista Brasileira de Botânica 26: 391-401.

Budowski, G. 1963. Forest succession in tropical lowland. Turrialba 13: 43-4.

Budowski, G. 1965. Distribution of tropical American forest species in the light of successional processes. Turrialba 15: 40-2.

Buzzato, C.R., Severo, B.M.A., Waechter, J.L. 2008. Composição florística e distribuição ecológica de epífitos vasculares na Floresta Nacional de Passo Fundo, Rio Grande do Sul. Iheringia, Série Botânica 63(2): 231-239.

Cervi, A.C.; Acra, L.A.; RodrigueS L.; Train, S.; Ivanchechen, S.L. \& Moreira, A.L.O.R. 1988. Contribuição ao conhecimento das epífitas (exclusive Bromeliaceae) em uma floresta de Araucária do Primeiro Planalto Paranaense. Insula 18: 75-82.

Cervi, A.C. \& Dombrowski, L.T.D. 1985. Bromeliaceae de um capão de floresta primária do Centro Politécnico de Curitiba (Paraná, Brasil). Fontqueria 9: 9-11.

Cervi,A.C. \& Borgo M. 2007. Epífitos vasculares no Parque Nacional do Iguaçu, Paraná (Brasil). Levantamento preliminar. Fontqueria 55(51): 415-422.

Coelho, C.P., Pinheiro, T.F. \& Laps, R.R. 2002. Epífitas como fonte de recursos para aves na Serra do Teimoso, Jussari, Bahia. In: Santos, F.A.M. \& Alves, T.F. (orgs.). Tópicos em Ecologia de Campo II (Pesquisa em Dossel) do Programa de Pós-graduação em Ecologia, IB, UNICAMP (dados não publicados).

Chapman, S.B. 1976. Methods in plant ecology. New York, J. Wiley.

Dettke, G.A.; Orfrini, A.C. \& Milaneze-Gutierre, M.A. 2008. Composição florística e distribuição de epífitas vasculares em um remanescente alterado de Floresta Estacional Semidecidual no Paraná, Brasil. Rodriguésia 59(4): 859-872. 
Dislich, R. 1996. Florística e estrutura do componente epifítico vascular na mata da Reserva da Cidade Universitária "Armando de Salles Oliveira", São Paulo, SP. Dissertação de Mestrado, Universidade de São Paulo, São Paulo.

Dislich, R. \& Mantovani, W. 1998. A flora de epífitas da reserva da Cidade Universitária "Armando de Salles Oliveira" (São Paulo, Brasil). Boletim de Botânica da Universidade de São Paulo 17: 61-83.

Dittrich, V.A.O.; Kozera, C. \& Silva, S.M. 1999. Levantamento florístico dos epífitos vasculares do Parque Barigüi, Curitiba, Paraná, Brasil. Iheringia, Série Botânica 52: 11-21.

Fidalgo, O. \& Bononi, V.R.L. 1989. Técnicas de coleta, preservação e herborização de material botânico. Série Documentos. Instituto de Botânica de São Paulo. Editora Silvana Vintecinco. 62 p.

Fischer, E.A. \& Araujo A.C. 1995. Spatial organization of bromeliad community in the Atlantic Rain Forest, South-eastern Brazil. Journal of Tropical Ecology 11: 559-567.

Giongo, C. \& Waechter, J.L. 2004. Composição florística e estrutura comunitária de epífitos vasculares em uma floresta de galeria na Depressão Central do Rio Grande do Sul, Brasil. Revista Brasileira de Botânica 3: 567-572.

Hatschbach, G.G \& Ziller, S.R. 1995. Lista Vermelha de Espécies Ameaçadas de Extinção no estado do Paraná, Curitiba, Secretaria Estadual do Meio ambiente de Curitiba, Biblioteca Nacional do Paraná.

IBGE, 1997. Divisão Municipal do Instituto Brasileiro de Geografia Estatística. Disponível em <http://www.ibge.gov.br $>$ (acesso em 20/02/2008).

Kersten, R.A. \& Kuniyoshi, Y.S. 2009. Conservação das florestas na Bacia do alto Iguaçú, Praná - Avaliação da comunidade de epífitas vasculares em diferentes estágios serais. Revista Floresta 39(1): 51-66.

Kersten, R.A. \& Silva, S.M. 2001. Composição florística e estrutura do componente epifítico vascular em floresta da planície litorânea na Ilha do Mel, Paraná, Brasil. Revista Brasileira de Botânica 24: 213-226.

Kersten, R.A. \& Silva, S.M. 2002. Florística e estrutura do componente epifítico vascular em Floresta Ombrófila Mista Aluvial do rio Barigüi, Paraná, Brasil. Revista Brasileira de Botânica 5: 259-267.

Kress, W.J. 1986. The systematic distribution of vascular epiphytes: an update. Selbyana 9: 2-22.

Maack, R. 1950. Mapa fitogeográfico do estado do Paraná. Curitiba Serviço de Geografia e Petrografia do Instituto de Biologia e Pesquisa Tecnológica, Secretaria de Agricultura, Indústria e Comércio e Instituto Nacional do Pinho.

Maack, R. 1981. Geografia Física do estado do Paraná. $2^{a}$ Ed., Rio de Janeiro, Livraria José Olympio. 442 p.
Madison, M. 1977. Vascular epiphytes: their systematic occurrence and salient features. Selbyana 2: 1-13.

Marchiori, J.N.C. 1995. Elementos de Dendrologia. Santa Maria, Editora Santa Maria, RS. 163 p.

Martins, V. L. R. 1989. Fitossociologia de florestas no Brasil: um histórico bibliográfico. São Leopoldo, Pesquisa série Botânica, 40: 103-164.

Miller, D. \& Warren, R. 1996. Orquídeas do Alto da Serra - da Mata Atlântica Pluvial do Sudeste do Brasil. Rio de Janeiro, Editora Salamandra, 1: 111-113.

Ministério do Meio Ambiente, 2008. Lista Oficial de Espécies da Flora Brasileira Ameaçada de Extinção, Brasil. Instrução normativa n⿳0 de 23 de setembro de 2008.

Missouri Botanical Garden 2009. (W3tropicos) Nomenclatural database. Disponível em <http://mobot.mobot.org/W3T/Search/vast.html> (acesso em 30 de julho de 2009).

Odum, E.P. 1972. Ecologia. 3 ed. Rio de Janeiro, Editora Guanabara Koogan.

Pinto, A.C.R., Demattê, M.E.S.P. \& Pavani, M.C.M.D. 1995. Composição florística de epífitas (Magnoliophyta) em fragmento de floresta no município de Jaboticabal, SP, Brasil. Científica 23: 283-589.

Pridgeon, A.M. \& Chase, M.W. 2001. A Phylogenetic reclassification of the Pleurothallidinae (Orchidaceae). Lindleyana 16: 235-271.

Pridgeon, A.M. \& Chase, M.W. 2002. Nomenclatural notes on Pleurothallidinae (Orchidaceae). Lindleyana 17(2): 98-101.

Proctor, M.; Yeo, P. \& Lack, A. 1996. The natural history of pollination. Harper Collins Publishers, London. 479 p.

Rizzini, C.T. 1997. Tratado de fitogeografia do Brasil: aspectos ecológicos, sociológicos e florísticos. 2 ed. Rio de Janeiro. Âmbito Cultural Edições.

Roderjan, C.V.; Galvão, F.; Kuniyoshi, Y. S.; \& Hatschback, G. 2002. As unidades fitogeográficas do estado do Paraná. Ciência e Ambiente 24: 75-92.

Smith,A.R.; Pryer, M.K.; Schuettpelz E.; Korall, P.; Schneider, H. \& Wolf, P.G. 2006. A classification for extant ferns. Táxon 55: 705-731.

Souza, M.L. 2003. Caracterização Geotécnica Básica dos Materiais Inconsolidados do Município de Campo Mourão, PR. Pp. 5-6. In: Encontro Geotécnico do Terceiro Planalto Paranaense, Maringá, PR. Stevens, P.F. 2006. Angiosperm Phylogeny Website. Disponível em:

$<$ http://www.mobot.org/MOBOT/research/APweb/>. Acesso em: 20/07/2009.

Waechter, J.L. 1992. O epifitismo vascular na Planície Costeira do Rio Grande do Sul. Tese de Doutorado, Universidade Federal de São Carlos, São Carlos.

Waechter, J.L. 1998. Epifitismo vascular em uma floresta de restinga do Brasil subtropical. Ciência e Natura 20: 43-66.

Versão eletrônica do artigo em www.scielo.br/abb e http://www.botanica.org.br/acta/ojs 